\title{
As consequências da globalizção para o Estado-Nação e para a Educação Superior
}

The CONSEQUENCES OF GLOBALIZATION CONCERNING THE STATE AND HIGHER EDUCATION

Verônica de Lourdes Pieto de Oliveira

\section{RESUMO}

Esse trabalho é parte integrante de uma pesquisa que teve por objetivo avaliar um projeto de integração universitária implantado em universidades do Mercosul. Neste texto abordam-se as causas que levaram à globalização econômica e como essa atingiu o Estado-Nação, transformando o cenário mundial e estimulando a integração de países em blocos regionais. Abordam-se também as consequências da globalização para a educação superior, a qual vem sendo convocada para atender aos anseios empresariais, na busca de aumentar a empregabilidade, o desenvolvimento tecnológico e econômico. O percurso metodológico teve como base o levantamento bibliográfico e a análise documental.

Palavras-chave: Blocos regionais. Integração universitária. Políticas supranacionais. 


\begin{abstract}
This study is part of a research which had the objective of evaluating a project of universitary integration implanted in universities from Mercosur. In this text, it is discussed about the causes that led to economical globalization and how it affected the Nation state, transforming the global scenery and stimulating the integration of countries in regional blocs. It is also discussed about the consequences of the globalization for higher education, which has been summoned to attend business willings, seeking to increase the employability and the technological and economical development. The methodological course had the bibliographic survey and the documentary analysis as a basis.
\end{abstract}

Keywords: regional blocs; universitary integration, supranational politics.

\title{
356 UNBE, REVISTA




\section{INTRODUÇÃO}

O presente trabalho é parte de uma pesquisa que teve como objetivo de avaliar o impacto do "Proyecto de Apoyo al Programa de Movilidad MERCOSUR en Educación Superior" (PMM) em algumas universidades mercosulinas ${ }^{1}$. O PMM foi um projeto co-financiado pela União Europeia (UE) e o Mercosul, cujo objetivo geral era de apoiar a conformação de uma cidadania MERCOSUL com sentimento de pertinência à região entre os membros da comunidade universitária dos quatros países membros do Mercosul2; e, como objetivo específico, pretendia apoiar a consolidação e expansão de um programa de mobilidade de estudantes universitários de graduação do MERCOSUL (COMUNIDAD EUROPEA/MERCOSUR, 2006).

Ao iniciarmos os estudos sobre oPMM sentimos a necessidade de entender o porquê dos países se organizarem em blocos regionais, o porquê de esses países aceitarem políticas formuladas por organismos que estão acima deles e o porquê de políticas supranacional visando à educação superior. Então, com base em estudos bibliográficos, entendemos que estas questões são decorrentes da globalização econômica, que redesenha o cenário mundial e transforma o papel do Estado, sendo seus efeitos sentidos nos mais diversos setores no âmbito do Estado, como na educação, por exemplo.

Globalização: o papel do Estado e o contexto das políticas SUPRANACIONAIS

Nos últimos tempos muito se têm falado sobre a globalização, a literatura sobre o assunto é ampla e variada, bem como seus pontos de vistas em relação ao termo. Segundo o sociólogo e teórico político Hirst e o economista Thompson,

[...] costumam-se dizer que estamos em uma era em que a maior parte da vida social é determinada por processos globais, em que culturas, economias e fronteiras nacionais estão se dissolvendo [...] os analistas sustentam que a economia mundial é dominada por forças de mercado incontroláveis e têm como seus principais atores econômicos e agentes

${ }^{1}$ Expressão encontrada nos trabalhos de Ventura (2003, p. 413) e de Accioly (2010, p. 99).

${ }^{2}$ Argentina, Brasil, Paraguai e Uruguai. Quando do lançamento do Programa a Venezuela ainda não compunha oficialmente o grupo de países membros do Mercosul, vindo a ter este status somente em julho de 2012, pela Decisão MERCOSUL/CMD/DEC. N $^{\circ} 28 / 12$, de $30 / 07 / 12$. 
de troca verdadeiras corporações transnacionais que não devem lealdade a Estado-nação alguma e se estabelecem em qualquer parte do mundo em que a vantagem de mercado impere. (1998, p. 13).

No entanto, esse processo, identificado como globalização, que implica em domínio da economia mundial, diluição das fronteiras nacionais e extinção do Estado-nação é questionado por estes autores, segundo os quais "[...] a globalização, da maneira como é concebida por seus defensores mais extremados, é basicamente um mito [...]" (Ibdem p. 14). Mito este que se trata de um fenômeno ideológico servindo a vários propósitos, como por exemplo, no plano editorial ajudando a “[...] vender jornais, revistas e livros superficiais. Nos planos econômicos e político, contribui para apanhar países ingênuos e despreparados na malha dos interesses internacionais dominantes", ressalta Batista Jr. (p. 1998, 125).

Esse mito se estabeleceu devido às mudanças estruturais iniciadas no final da era pós-1945. Hirst e Thompson apontam que

[...]. Um grande número de mudanças significativas encerrou um período de prolongado crescimento econômico e de pleno-emprego nos países avançados, sustentado por estratégias de ativa intervenção estatal nacional e por um regime de administração multilateral da política comercial e monetária sob hegemonia dos Estados Unidos [...] (1988, p.19).

Essas mudanças iniciaram com o colapso do sistema de Bretton Woods ${ }^{3}$ e da crise do Petróleo da $\mathrm{OPEP}^{4}$, causando uma instabilidade econômica nas principais economias da década de 70 ao início de 80 , enfraquecendo os regimes políticos anteriores. Esse período de turbulência levou as instituições financeiras e os industriais a buscarem alternativas para compensar as incertezas domésticas, resultando em "[...] grandes empréstimos de bancos para o Terceiro Mundo durante a inflacionária década de 70, o crescimento do mercado eurodólares e o crescente comércio exterior em relação do PIB nos países avançados" (Ibidem). Houve uma aceleração da política pública de internacionalização dos

\footnotetext{
${ }^{3}$ Sistema iniciado em 1944 na Conferência Monetária e Financeira das Nações Unidas, realizada em Bretton Woods, estado de New Hampshire, nos Estados Unidos, onde se fizeram presentes por 730 delegados e 40 países, que objetivavam a reconstrução do capitalismo mundial a partir de um sistema de regras que regulasse a política econômica internacional. Ficou definido em tal Sistema que cada país estaria obrigado a manter a taxa de câmbio de sua moeda congelada ao dólar, com margem de manobra por volta de $1 \%$. Já o dólar ficaria ligado ao valor do ouro em uma base fixa, com isto possibilitaria certa estabilidade monetária (IPEA, 2009).

${ }^{4}$ Organização dos Países Exportadores de Petróleo.
}

\section{UNIBE $\mid \begin{aligned} & \text { REVISTA } \\ & \text { CIENTIFICA }\end{aligned}$}


mercados financeiros, abandonando o controle de cambio. Nesse período havia uma tendência à desindustrialização na Inglaterra e nos Estados Unidos, levando ao medo da competição estrangeira em relação a emprego. Dentre as mudanças também estão às questões do desenvolvimento rápido de novos países industrializados no Terceiro Mundo e suas inserções nos mercados de Primeiro Mundo e a flexibilização dos métodos de produção, apontam Hirst e Thompson (1988, p. 19-20).

Estas transformações levaram à ideia de enfraquecimento do papel do Estado-Nação e das políticas nacionais, sendo estas comparadas a uma “[...] política municipal, uma questão de oferecer serviços triviais [...]" (Ibidem, p. 273). Os autores afirmam que realmente muita coisa mudou no papel do Estado-nação desde a era Keynesiana ${ }^{5}$, sendo menos autônomos, com menos controle exclusivo sobre os processos econômicos e sociais dentro de seus territórios, além de serem menos capazes de manter a singularidade nacional e a homogeneidade cultural. Em relação à autonomia, os autores apontam, por exemplo, a questão da guerra, dizendo que os Estados aceitam um nível de interferência para tornar a paz possível. Em relação à questão social, eles dizem que o que está ameaçada é a ideia de uma cultura nacional exclusiva, mas que as tradições locais continuarão a coexistir com as práticas cosmopolitas e,em relação à economia, os autores, contrapondo a ideia dos teóricos radicais da globalização de que as maiores companhias seriam beneficiadas com um meio internacional desregulado, ressaltam que

[...]. Regras de comércio presumíveis, direitos de propriedade estabelecidos e internacionalmente comuns, e estabilidade da taxa de cambio constituem um nível de segurança elementar que as empresas necessitam planejar para o futuro e, portanto, uma condição de investimento e crescimento contínuo. As empresas não podem, por si só, criar essas condições, mesmo quando são transnacionais. A estabilidade na economia internacional só pode ser obtida se os Estados combinam regulá-la e concordam com objetivos comuns e padrões de governabilidade. As empresas podem querer livre comércio e regimes comuns de padrões comerciais, mas só podem tê-los, se

${ }^{5}$ Teoria econômica que se destacou nos anos 30 , época em que o capitalismo vivia uma grave crise, provocada pelo sistema liberal clássico adotado pelos países, qual defendia a nãointervenção do Estado na economia, qual seu propulsor era Adam Smith. Em contraposição ao liberalismo clássico, o economista britânico John Maynard Keynes propôs, em sua obra Teoria Geral do emprego, do juro e da moeda, uma teoria na qual defendia a intervenção do Estado como forma de equilibrar a economia, realizando ações que vinham a conceder benefícios sociais que garantiam à população um padrão mínimo de vida. 
os Estados trabalham juntos para realizar a regulação internacional comum (Ibidem, p.288).

Os pensamentos dos autores nos remetem a Bob Jessop, quando do seu reexame dos argumentos global de Polantzas. Em seu texto o autor aponta a existência de tendências gerais na transformação do poder do Estado advindas da globalização.

Primeiramente ele diz que há uma tendência à desnacionalização do Estado, empiricamente refletida no esvaziamento do aparelho do Estado nacional e que a mesma ocasiona a perda da soberania estatal em alguns aspectos, à medida que transfere para corpos supranacionais os poderes para a elaboração de normas ou decisões, as quais vinculam o Estado nacional. Contudo, o autor alerta que essa tendência não deve ser confundida com a ascensão de um "Estado global", pois um estado assim se tornaria o equivalente a um "Estado mundial", único.

A segunda tendência apontada pelo autor é a desestatização do sistema político, a qual reflete em um deslocamento do governo para governança ${ }^{6}$, ou seja, há uma necessidade de centralizar o Estado na regulação social econômica para que haja o favorecimento de parcerias entre organizações governamentais, paragovernamentais e não governamentais, cabendo ao Estado a tarefa de coordenação dessas parcerias, necessidade que segundo o autor, não exige uma perda de poder do governo, tampouco indica a desnecessidade do Estado, pois a governança favorece a capacidade para a projeção de influência do Estado e para a asseguração de seus objetivos, continuando o Estado a ter relevante importância na sociedade, visto que cabe a ele manter a coesão social com legitimidade, porém com menos exclusividade de controle, conforme apontado por Hirst e Thompson (1998).

A última tendência apresentada pelo autor é a internacionalização dos regimes de formulação de políticas, a qual se traduz nas influências do contexto internacional das políticas econômicas e sociais do Estado, na medida em que esse vai se tornando mais envolvido com a competitividade mundial, adequando as suas ações às exigências da globalização econômica (JESSOP, 1997).

\footnotetext{
${ }^{6}$ A governança pública é vista “"[...] como um modelo alternativo as estruturas governamentais hierarquizadas, implicando que os Governos sejam muito mais eficazes em um marco de economia globalizada, não somente atuando com capacidade máxima de gestão, mas também garantindo e respeitando as normas e valores próprios de uma sociedade democrática" (OLIVEIRA, 2010, p. 2).
} 
Delineamos as origens da globalização atual e suas implicações para o Estado, contudo, ainda nos falta conceituar esse fenômeno. Dale (2004) define tal fenômeno como "[...] um conjunto de dispositivos políticos econômicos para a organização da economia global, conduzido pela necessidade de manter o sistema capitalista, mais do que qualquer outro conjunto de valores. [...]" (Ibidem, p. 435).

Para este autor a globalização é construída por três conjuntos de atividades relacionadas entre si, quais sejam, econômicas, políticas e culturais, podendo esta ser considerada como hiper-liberalismo, governação sem governo e mercadorização e consumismo, respectivamente, quais se configuram na base da expansão contínua e na legitimação do sistema capitalista, não deixando de atingir as políticas educacionais.

Ante a necessidade de se manter, as funções desse sistema vão se inserindo na estrutura política e social ocasionando mudanças no Estado e nos seus mais diversos campos, levando à transformação da organização do espaço e das relações sociais e econômicas, incidindo, assim, em uma nova visão do papel do Estado-nação. Porém, podemos constatar no estudo acima que, apesar do Estado-nação ${ }^{7}$, ou Estado nacional ${ }^{8}$ (os dois termos são encontrados na literatura) ter sido limitado em alguns aspectos, ele guarda sua importância como estrutura política para ao sistema posto, tendo nele o papel de gestor, ou seja, coordenador, negociador e regulador; ele não é mais heroico, lembrando-nos de uma passagem de Renato Ortiz ${ }^{9}$ (2006), nem detentor do poder de império ${ }^{10}$ como disse Bobbio (2007), mas conserva sua importância nesses outros tempos, estando hoje entre as suas funções a de manter a coesão social ante a dinâmica do mundo globalizado.

A globalização transforma o papel do Estado e o impõem novas demandas e desafios, cabendo a ele buscar soluções, porém numa dinâmica diferente

${ }^{7}$ HIRST \& THOMPSON, 1998; ORTIZ, 2006; JANELA, 2003

${ }^{8}$ JESSOP, 1997

9 “O Estado-nação já não tem a mesma força de antes. Marx dizia que a burguesia de sua época não tinha mais um papel heróico de criadora de uma civilização. O Estado-nação, parafraseando Marx, já não tem mais o mesmo papel heróico. Isto não significa que ele desapareceu ou vá desaparecer. Ele ainda tem uma enorme importância, mas os tempos são outros" (ORTIZ, 2006).

10 “[...] Um Estado Moderno, no qual a sociedade civil é constituída por grupos organizados cada vez mais fortes, está atravessado por conflitos grupais que se renovam continuamente, diante dos quais o Estado, [...], desenvolve a função de mediador e de garante mais do que a de detentor do poder de império, segundo a representação clássica da soberania [...]" (BOBBIO, 2007, p. 26). 
da que se tinha anteriormente, onde o poder era centrado no governo. Agora o Estado comporta outros atores de poder ${ }^{11}$, com os quais ele divide sua soberania, assumido assim uma nova perspectiva de gestão no atual cenário mundial.

Considerando essas novas demandas e desafios, os países têm buscado, através da união, alternativas para se fortalecerem e para encontrarem soluções aos problemas que já não podem ser resolvidos isoladamente, ensejando assim a integração regional, vista no discurso europeu como "[...] um dos meios para atingir um desenvolvimento sustentável e socialmente harmonioso e também um instrumento de inserção competitiva na economia internacional" (COMUNIDADE EUROPEIA, 1996, p. 21).

A regionalização redesenha o cenário geográfico e político mundial, passando a ter na união de países um arranjo político e econômico para fazer frente às consequências da globalização. A partir dessa integração o cenário geográfico e político mundial ganhou um novo formato.

A multiplicação dos acordos e blocos econômicos regionais constitui um dos fenômenos mais marcantes do pós-Guerra Fria. A antiga paisagem plana, onde se destacava o cume praticamente solitário da Comunidade Européia, foi preenchida por cordilheiras, montanhas e morros de blocos poderosos, intermediários ou pífios, ou apenas de projetos ambiciosos de megablocos transcontinentais (MAGNOLI, 1997, p. 1).

Nesta arena destacamos a UE e o Mercosul ${ }^{12}$, sendo que a primeira já se encontra em um estágio mais avançado e o segundo ainda é incipiente, mas ambos objetivam a integração regional e o fortalecimento de seus respectivos blocos. Essa "integração pressupõe a criação de centros de decisões comunitários que possuem competências atribuídas pelos Estados-membros e deles subtraídas. Na integração, o processo é voltado para a satisfação dos interesses comunitários" (SANTOS, 2008, p. 178).

\footnotetext{
"Além dos próprios blocos serem um dos atores na governança dos Estados, outros atores são apontados, como os organismos internacionais (Organização das Nações Unidas - ONU, Organização das Nações Unidas para educação, ciência e cultura - UNESCO, Organização para a Cooperação e o Desenvolvimento Econômico - OCDE, Organização Mundial da Saúde - OMS, Organização dos Estados Americanos - OEA, Organização do Tratado do Atlântico Norte - OTAN, Banco Internacional para Reconstrução e Desenvolvimento BIRD, Organização Mundial do Comércio - OMC, Organização Internacional do Trabalho - OIT, entre outros), as agências e empresas transnacionais, entre outros.

${ }^{12}$ A título de exemplo ainda citamos: a Associação das Nações do Sudeste da Ásia (ASEAN); Cooperação Econômica da Ásia e do Pacífico (APEC); Tratado Norte-Americano de Livre Comércio (NAFTA).
}

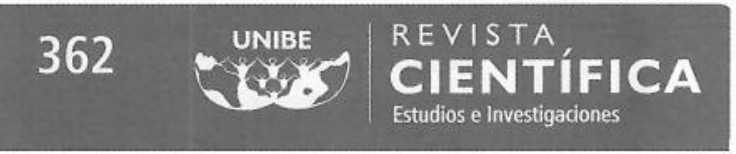


Assim, na união de países é estabelecida uma instância superior com objetivos de orientação, normatização e elaboração de políticas públicas dirigidas "[...] por um meta-estado [...]" (AZEVEDO, 2007, p. 139), abrangendo os mais diversos campos dentro dos respectivos Estados que compõem os blocos.

Ao cuidar do processo de convergência da educação superior na Europa, Azevedo (2007) observa que a própria UE pode ser considerada um Estado, ou seja, um Estado transnacional, pois "[...] os países reunidos cedem parte de sua soberania com vistas à construção de uma região integrada em termos econômicos, sociais, políticos, culturais e educacionais" (Ibidem, p.136).

Analisando as considerações de Azevedo (2007) e de Santos (2008), caminhamos ao entendimento do por que da aceitação e implantação, pelos países que compõem um bloco regional, de políticas elaboradas por uma organização supranacional. Essa compreende os Estados que a forma, possuindo competências atribuídas e subtraídas por e desses Estados, como disse Santos (2008), sendo eles, assim, a própria organização supranacional, ou seja, um Estado Transnacional (AZEVEDO, 2007).

O Estado não é homogêneo, ele se constitui em "[...] um campo de contradições e de lutas. [...] um campo social ocupado por atores sociais com interesses comuns e também opera políticas públicas que vão influenciar o conjunto da população a ele subordinado" (Ibidem, p. 138), assim o é o bloco regional, comportando em seu seio todas as tensões e contradições inerentes às sociedades que o compõe, necessitando articulá-las para se consolidar como região integrada e competitiva.

A educação superior não fica imune a essas questões, ao contrário, ela sofreu as consequências da globalização e da integração regional, tendo que se adaptar às novas exigências desses processos.

\section{A EdUCAÇão SUPERior no Cenário globalizado}

O alcance da globalização é amplo e seria ingenuidade pensar que "[...] ficaria restrita ao âmbito econômico-financeiro; que não envolvesse de modo abrangente e incisivo os campos sociais, da cultura, da ciência, do conhecimento [...]" (SGUISSARDI, 2005, p. 7). A educação não ficou imune a esse fenômeno, visto que ela está ligada ao caráter político, econômico e cultural, sendo que os quadros regulatórios nacionais, em maior ou menor medida, são moldados e determinados por forças supranacionais e também por forças político-econômicas nacionais. São 
"[...] por estas vias indiretas que a globalização tem os seus mais óbvios e importantes efeitos sobre os sistemas educativos nacionais" (DALE, 2004, p. 441).

Oliveira (2009) aponta as seguintes consequências da globalização para a educação:

a crescente centralidade da educação na discussão acerca do desenvolvimento e da preparação para o trabalho, decorrente das mudanças em curso na base técnica e no processo produtivo; b) a crescente introdução de tecnologias no processo educativo, por meio de softwares educativos e pelo recurso à educação a distância; c) a implementação de reformas educativas muito similares entre si na grande maioria dos países do mundo; d) a transformação da educação em objeto do interesse do grande capital, ocasionando uma crescente comercialização do setor (p. 740).

Tais consequências também são sentidas na educação superior, que é considerada fundamental para formação de mão-de-obra especializada, visando atender ao setor produtivo, assim como para a busca de inovação e tecnologia, além de, devido à sua expansão, poder ser considerada atualmente como uma mercadoria passível de comercialização (Ibidem).

Ao retrocedermos na história, observamos que a universidade teve sua origem na Idade Média, a partir do século XII e, segundo Dias Sobrinho (2005), sua expansão esteve ligada à consolidação do Estado, para a qual se necessitava a "[...] ampliação da oferta educacional a um número cada vez maior de indivíduos [...]" (Ibidem, p. 65). As primeiras universidades surgiram na Europa e seu modelo passou a ser adotado em todo o mundo, porém, após a Segunda Guerra Mundial, a educação superior reconfigurou-se e passou a ser um fator importante para o desenvolvimento dos países industrializados, incidindo, assim, na prevalência do modelo universitário norte-americano.

Essa mudança é explicada, segundo Dias Sobrinho (2005), em grande parte pela importância da tecnologia e da globalização econômica. Essas geraram transformações em níveis nacional e internacional, promovendo ajustes estruturais no interior dos Estados e, conforme Ferreira (2010), esses ajustes foram realizados em consonância com os organismos multilaterais, como o Fundo Monetário Internacional (FMI), Banco Interamericano de Desenvolvimento (BID), Banco Mundial (BM),

\section{UNIBE REVISTA


Organização Mundial do Comércio (OMC) entre outras ${ }^{13}$, os quais propiciam mudanças no papel do Estado e em suas respectivas políticas educacionais.

Nesse cenário, "[...] a concepção do conhecimento e do ensino superior passa a ser compreendida como bens privados, associados à transformação da ciência, da tecnologia e da informação como importantes forças produtivas capitalistas [...]" (FERREIRA, 2010, p. 67), espera-se que o ensino superior, além de produzir conhecimento para atender os interesses do setor produtivo, forme mão-de-obra para o mercado com o menor tempo possível despendido nos bancos escolares, exigindo cursos mais curtos e currículos mais flexíveis, abarcando novas formas de financiamento e de provedores ${ }^{14}$ educacionais ${ }^{15}$.

A associação da educação superior à capacidade produtiva econômica fez com que ela passasse a ser vista como um importante instrumento para o desenvolvimento econômico dos países, bem como para torna-los competitivos no cenário mundial, o que a coloca no centro das agendas governamentais, tanto nacionais quanto supranacionais.

Contudo, a importância do ensino superior não para por aí, visto que as Instituições de Ensino Superior (IES) estão sendo requisitadas para colaborar nos processos de integrações regionais ${ }^{16}$, tendo como tarefa influenciar na construção de uma cidadania regional, combatendo o nacionalismo estrito, pois considerando que ela é "[...] um setor estratégico para o desenvolvimento de um país e um fator de integração entre países

${ }^{13}$ Nesse rol acrescentamos a União Europeia que vem se colocando como exemplo de integração regional e, também, de integração universitária para as outras regiões do mundo, como veremos no decorrer do trabalho.

14 “[...] Na literatura especializada, a noção de "novos provedores" refere-se, por um lado, a um setor de empresas e corporações, distintas do setor privado tradicional, que se fez presente na oferta da educação superior através das universidades e centros de ensino superior de caráter empresarial ou como designados na língua inglesa, "for profit". Por outro lado, se menciona as organizações, públicas ou privadas, que oferecem educação superior (presencial ou à distância) através de meios eletrônicos, assim como as organizações que oferecem meios de suporte e serviços complementares a esta categoria de 159 provedores. Essa educação superior virtual passou a representar uma oportunidade de investimento atrativa para empresas com fins de lucro, mas também uma possibilidade de expansão para o setor público através do sistema de telecomunicações e graças à relativa ausência de controles" (LAUS, 2012, p. 158).

${ }^{15}$ Estas são algumas das novas características impressas à educação superior, advindas do modelo estado-unidense, qual provocou transformações neste nível de ensino das outras partes do mundo, apontados por Dias Sobrinho (2005, p. 66).

${ }^{16}$ Como visto anteriormente, a integração regional surge em consequência do processo de globalização que impulsiona os países a se unirem em blocos regionais. 
e nações, está inserida efetivamente no processo de integração regional [...]" (AZEVEDO, 2008, p. 875).

Sendo assim, “[...] as políticas, os programas e as práticas da educação superior são cada vez mais cooptados e dimensionados por interesses políticos e econômicos geoestratégicos mais amplos [...]" (ROBERTSON, 2009, p. 407), destacando-se nas ações estabelecidas por meio dos acordos regionais que envolvem a Europa e mesmo a América Latina, voltadas para impulsionar o desenvolvimento econômico, por meio da inovação e da formação de mão de obra, bem como para atuar na consolidação da integração regional. Krawczyk (2008) aponta que

Nos últimos 20 anos é possível observar também, concomitantemente à formulação de políticas homogeneizantes que atingem as universidades, o esboço de um novo processo de transformação, talvez de 'transnacionalização', na medida em que a universidade começa a sentir as pressões dos Estados, das sociedades e do mercado no contexto do novo estágio da globalização e da competitividade internacional que tem levado à necessidade de integração com outros países para a construção de blocos regionais. Acontecendo quase simultaneamente, estes dois processos trazem uma nova tensão no cenário universitário, principalmente no âmbito da produção do conhecimento, entre um incipiente processo de 'transnacionalização' ou regionalização e as políticas de homogeneização sob o comum denominador de políticas de integração da região (p. 44).

Tem-se notado na Europa e, mais recentemente e ainda incipiente, no Mercosul, políticas supranacionais visando a integração do ensino superior para responder às demandas e desafios geradas pelo processo de globalização econômica. Krawczyk (2008) ressalta que hoje já se pode encontrar um importante debate sobre o processo de integração regional das universidades da Europa e também nas da América do Norte e Central, devido às políticas governamentais implementadas na construção dos blocos da União Europeia e do Tratado de Livre Comércio da América do Norte, o Nafta. No Mercosul, apesar de existirem políticas supranacionais, governamentais e universitárias de regionalização, esse debate ainda é incipiente (KRAWCZYK e SANDOVAL, 2012).

A Europa viu surgir, na última década, um movimento de convergência do ensino superior com vista à construção de Espaço Europeu do Ensino Superior (EEES). Esse movimento ficou conhecido como Processo de Bolonha, que tomou uma dimensão continental, uma vez que trata-se de

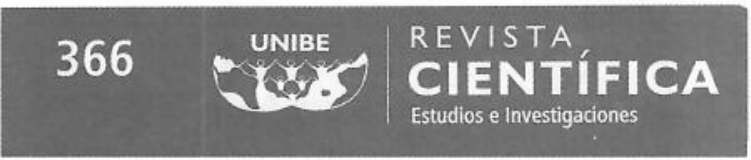


um projeto para a Europa e não só para a União Europeia. Esse projeto veio em resposta aos fenômenos da globalização, na busca de consolidar a regionalização europeia, torná-la mais competitiva no cenário mundial, mais atrativa no campo da educação superior e reconhecida mundialmente nesse nível de ensino. Esse processo já é considerado avançado em termos de convergência e regionalização universitária.

No Mercosul, embora existam instâncias ${ }^{17}$ instituídas para a integração do ensino superior e " [...] apesar de inúmeros documentos assinados (tratados, convenções e resoluções), pouco tem se avançado para a integração dos sistemas nacionais/federais de educação superior com vistas a um espaço compartilhado de formação acadêmica e de pesquisa [...]" (AZEVEDO, 2008, p. 876).

Os blocos regionais, cada um no seu ritmo, têm buscado investir em políticas para a integração universitária, uma vez que o ensino superior está sendo concebido como instrumento impulsionador de desenvolvimento econômico e de contribuição para com o processo de transnacionalização dos espaços regionais, tendo, dessa maneira, centralidade nas agendas governamentais, pois “[...] no contexto da globalização/regionalização, a questão da constituição de uma força suporte de Recursos Humanos é de extrema importância para a implantação e consolidação da rearticulação econômico-social proposta. [...]" (MOROSINI, 1998, p. 48).

Contudo, as políticas de integração universitária, por vezes, se revestem de verticalidade, trazendo como consequências a resistência à implantação dessas políticas, acusações de desrespeito às especificidades e autonomias das IES e conflitos internos. Assim, o debate sobre a integração universitária precisa ser fortalecido no meio acadêmico, pois [...] é a participação que leva à adesão e ao comprometimento, sem ela há temor que o processo se burocratize e seja superficial (DIAS SOBRINHO, 2005, p. 11), visando a real integração e fortalecimento do ensino superior nos blocos regionais para enfrentar as mudanças causadas pelo processo de globalização e, para além de atender aos interesses mercadológicos, formar o cidadão para o exercício da cidadania crítica e criativa (Ibidem).

${ }^{7}$ O Setor Educacional do Mercosul (SEM) é o responsável por políticas de educação no bloco, sendo que a educação superior fica a cargo da Comissão Regional Coordenadora de Educação Superior do Mercosul (CRS), uma das coordenadorias do SEM. 


\section{REFERÊNCIAS}

ACCIOLY, Elizabeth. Mercosul e União Européia: estrutura jurídicoinstitucional. 4 ed. Curitiba: Juruá, 2010.

AZEVEDO, Mário Luiz Neves. A integração dos sistemas de educação superior na Europa: de Roma a Bolonha ou da integração econômica à integração acadêmica. Educação Temática Digital - ETD, Campinas, v. 9, n. esp., p.133-149, dez. 2007.

A Formação de Espaços Regionais de Educação Superior: um olhar meridional para o MERCOSUL. Avaliação. Campinas; Sorocaba, SP. V.13, n. 3, nov. 2008.

BARRAL, Welber. O Protocolo de Olivos e o Mercosul. Sequiência. UFSC, Florianópolis, SC, Brasil, V. 23 n. 44, 2002, p. 149-165. Disponível em: <http://periodicos.ufsc.br/index.php/sequencia/issue/ view/1489>. Acesso em: 10.03.2011.

BATISTA JR., Paulo Nogueira. Mitos da Globalização. Estudos Avançados, 1998, p. 125-183. Disponível em: < http://www.scielo.br/ pdf/ea/v12n32/v12n32a12.pdf >. Acesso em 02.05.2013.

Convenio de Financiación entre la Comunidad Europea y el MERCOSUR: Apoyo al Programa de Movilidad MERCOSUR en Educación Superior. [s.1.], 2006. Disponível em: <http://www.mercosur. $\mathrm{int} / \mathrm{msweb} /$ Normas/resa08.html $>$. Acesso em 20.10.2011.

CEPAL. Acerca de la CEPAL. Santiago do Chile, 2000. Disponível em: <http://www.cepal.org/cgibin/getProd.asp?xml=/brasil/noticias/ paginas/2/5562/p5562.xml\&xsl=/brasil/tpl/p18f.xsl\&base=/brasil/tpl/ top-bottom.xsl>. Acesso em 28.04.2013.

DALE, Roger. Globalização e educação: demonstrando a existência de uma "Cultura Educacional Mundial Comum" ou localizando uma "Agenda Globalmente Estruturada para a Educação"?. Educ. Soc. 2004, vol.25, n.87, p. 423-460. Disponível em: <http://www.si.ips.pt/esce_si/ web_gessi_docs.download_file?p_name $=$ F334899515/Dale $\% 20 \% 20$ Globaliza\%E7\%E3o\%20e\%20educa\%E7\%E3o.pdf $>$. Acesso em 20.04.2013.

\section{UNIBE ${ }^{\text {REVISTA }}$ CIENTÍFICA


DIAS SOBRINHO, José. Dilemas da educação superior no mundo globalizado: sociedade do conhecimento ou economia do conhecimento? São Paulo: Casa do Psicólogo, 2005.

HIRST, Paul. THOMPSON, Grahame. Globalização em questão: a economia internacional e as possibilidades de governabilidade. Tradução Wanda Caldeira Branst. Petrópolis, RJ: Vozes, 1998.

IPEA. Desafios do Desenvolvimento. História. Bretton Woods. Ano 6, Ed. 50, Brasília, 2009. Disponível: em <http://desafios.ipea.gov.br/ index.php?option $=$ com_content $\&$ view $=$ article $\& i d=2247$ : catid $=28 \&$ Ite mid=23>. Acesso em: 05.05.2013.

JESSOP, Bob.A globalização e o Estado nacional. Crítica Marxista, 1997, p. 9-45. Disponível em:<http://www.ifch.unicamp.br/criticamarxista/ arquivos_biblioteca/artigo39critica7_02.pdf>. Acesso em: 01.05.2013.

KRAWCZYK, Nora. As Políticas de Internacionalização das Universidades no Brasil: o caso da regionalização no Mercosul. Jornal de Políticas Educacionais. $\mathrm{n}^{\circ} 4$ - julho-dezembro de 2008, p. 41- 52. Disponível em: < http://www.jpe.ufpr.br/n4_5.pdf>. Acesso em 12.08.2012.

KRAWCZYK, Nora Rut. VIEIRA, Vera Lúcia. A reforma educacional na América Latina nos anos 90: uma perspectiva histórico-sociológica. Revista Latinoamericana de Educación Comparada - RELEC, $\mathrm{n}^{\circ}$ 1, 2010. Disponível em: <http://saece.org.ar/relec/revistas/1/art1.pdf>. Acesso em 20.06.2013.

OLIVEIRA, Justino de. Governança pública e parcerias do Estado: a relevância dos acordos administrativos para a nova gestão pública. 2010. Disponível em: <http://www.academia.edu/821570/GOVERNANCA_ PUBLICA_E_PARCERIAS_DO_ESTADO_A_RELEVANCIA_DOS_ ACORDOS_ADMINISTRATIVOS_PARA_A_NOVA_GESTAO_ PUBLICA > . Acesso em 22.04.2013.

OLIVEIRA, Romualdo Portela. A transformação da educação em mercadoria no Brasil. Educ. Soc., Campinas, vol. 30, n. 108, out. 2009, p. 739-760. Disponível em: <http://www.cedes.unicamp.br>. Acesso em 17.06.2013.

ORTIZ, Renato. Desafi(n)ando o coro global. Entrevista a Álvaro Kassab. Jornal da Unicamp, Ed. 325, de 29 maio a 4 de junho. Campinas, 
2006. Disponível em: <http://www.unicamp.br/unicamp/unicamp_hoje/ ju/maio2006/ju325pag4-5.html> Acesso em 05.03.2013.

SGUISSARDI, Valdemar. Rumo à universidade mundial: e a universidade será feita à sua imagem e semelhança. In Valdemar Sguissard; Maria Estela Dal Pai; Marília Morosini. Internacionalização, gestão democrática e autonomia universitária em questão. Brasília: Instituto Nacional de Estudos e Pesquisas Educacionais Anísio Teixeira, 2005.

VENTURA, Deyse de Freitas Lima. As assimetrias entre o Mercosul e a União Europeia: os desafios de uma associação inter-regional. Barueri, SP: Manole, 2003.

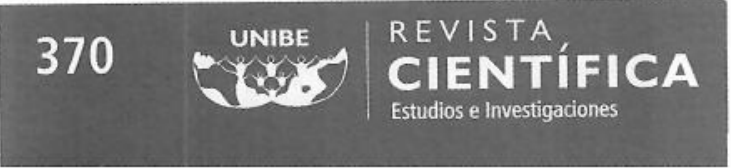

